\title{
A 6-Month Study Comparing Efficacy, Safety, and Tolerability of the Preservative-free Fixed Combination of Tafluprost $0.0015 \%$ and Timolol $0.5 \%$ versus Each of Its Individual Preservative-Free Components
}

\author{
Norbert Pfeiffer $\cdot$ Carlo E. Traverso $\cdot$ Katrin Lorenz $\cdot$ Ville Saarela $\cdot$ Johanna Liinamaa \\ Hannu Uusitalo $\cdot$ Yury Astakhov $\cdot$ Ernest Boiko $\cdot$ Auli Ropo \\ To view enhanced content go to www.advancesintherapy.com \\ Received: August 6, 2014 / Published online: December 2, 2014 \\ (c) The Author(s) 2014. This article is published with open access at Springerlink.com
}

\section{ABSTRACT}

Introduction: The efficacy, safety and tolerability of the preservative-free (PF) fixed combination (FC) of tafluprost $0.0015 \%$ and timolol $0.5 \%$ (once daily) were compared to those of the individual components (PF

Trial Registration: ClinicalTrial.gov \#NCT01292460.

For the Preservative-free Tafluprost/Timolol Fixed Combination Study Group.

The investigators who participated in the Preservativefree Tafluprost Fixed Combination Study Group are listed in Appendix.

Electronic supplementary material The online version of this article (doi:10.1007/s12325-014-0163-3) contains supplementary material, which is available to authorized users.

N. Pfeiffer $(\bowtie) \cdot K$. Lorenz

Department of Ophthalmology, Mainz University

Medical Center, Langenbeckstr. 1, 55101 Mainz,

Germany

e-mail: norbert.pfeiffer@unimedizin-mainz.de

C. E. Traverso

Clinica Oculistica, Di.N.O.G.M.I., University of

Genoa, IRCCS Azienda Ospedaliera Universitaria

San Martino-IST, Genoa, Italy

V. Saarela $\cdot$ J. Liinamaa

Department of Ophthalmology, Medical Research Center, Oulu University Hospital, University of

Oulu, Oulu, Finland tafluprost $0.0015 \%$ once daily and PF timolol $0.5 \%$ twice daily) in patients with open-angle glaucoma or ocular hypertension inadequately controlled on prior timolol or prostaglandin monotherapy for 6 months.

Methods: A stratified, double-masked, randomized, multicenter phase III study was conducted. A total of 189 prior timolol users were randomized within the timolol stratum (TS) to receive either FC $(n=95)$ or timolol $0.5 \%$ (TIM; $n=94$ ). Furthermore, a total of 375 prior prostaglandin analog (PGA) users were randomized within the prostaglandin stratum (PS) to receive either FC $(n=188)$ or tafluprost $0.0015 \%$ (TAF; $n=187$ ). To be eligible for participation in the study, the patients were required to have an intraocular pressure (IOP)

H. Uusitalo

Department of Ophthalmology, University of Tampere and TAUH Eye Center, Tampere, Finland

Y. Astakhov

First Pavlov State Medical University of St.

Petersburg, St. Petersburg, Russia

E. Boiko

Military Medical Academy, St. Petersburg, Russia

A. Ropo

Santen Oy, Clinical Research and Medical Affairs, Helsinki, Finland 
of $\geq 22 \mathrm{mmHg}$ when on timolol (TIM) or of $\geq 20 \mathrm{mmHg}$ when on PGA in either treated eye at the screening and end-of-run-in visits. In addition to these, the study included visits at baseline, 2 and 6 weeks, 3 and 6 months and at a post-study visit. IOP was measured at 8 a.m., 10 a.m., 4 p.m., and 8 p.m.

Results: In the TS, a significant reduction from baseline IOP was seen with FC and TIM throughout the study. Average diurnal IOP change from baseline at month 3 was $-8.55 \mathrm{mmHg}$ (32\%) for FC and $-7.35 \mathrm{mmHg}$ (28\%) for TIM. The model-based treatment difference (FC-TIM) was $-0.885 \mathrm{mmHg}$ [95\% confidence interval (CI) -1.745 to -0.024 ; $p=0.044]$ demonstrating the superiority of FC over TIM. In the PS, a significant reduction in IOP was seen with both FC and TAF throughout the study. The average diurnal IOP change from baseline at month 3 was $-8.61 \mathrm{mmHg}$ (33\%) for FC and $-7.23 \mathrm{mmHg}$ (28\%) for TAF. The model-based treatment difference (FC-TAF) was $-1.516 \mathrm{mmHg}$ (95\% CI -2.044 to -0.988 ; $p<0.001)$ demonstrating the superiority of FC over TAF. In the TS, related ocular adverse events (AEs) were more frequent for patients treated with FC compared to TIM (16.8\% versus 6.4\%), whereas related non-ocular AEs were more frequent with TIM compared to FC $(2.1 \%$ versus $0.0 \%)$. In the $\mathrm{PS}$, $\mathrm{AEs}$ were similarly distributed between FC and TAF. The frequency of conjunctival hyperemia of FC was low (6.4\%).

Conclusion: The preservative-free fixed combination of tafluprost and timolol provided a substantial and significant IOP reduction in both strata. The IOP reduction was superior to both tafluprost $0.0015 \%$ and timolol $0.5 \%$ when given as monotherapies. Overall, the study treatments were safe and well tolerated.

Funding: Santen Oy, Tampere, Finland.
Keywords: Glaucoma; Fixed combination; Preservative free; Preservatives; Prostaglandins; Tafluprost; Timolol

\section{INTRODUCTION}

The medical treatment of ocular hypertension and glaucoma is focused on reducing intraocular pressure (IOP) to reach and maintain the individual target IOP. However, for many patients, a single medication is not sufficient in this respect $[1,2]$. If the target IOP cannot be achieved using a monotherapy, a combination of drugs with different mechanisms of action is recommended [3]. In recent years, the use of fixed combination (FC) glaucoma medications in patients with glaucoma or ocular hypertension has substantially increased. Fixed combinations contain two medications in a single bottle, which may be more convenient for the patient because fewer instillations and bottles are used, and thus likely improves compliance and adherence because of the simpler treatment regimen [4]. Multiple topical therapies may also be associated with a higher incidence of side effects [5]. Increased exposure to preservatives may have untoward effects on the ocular surface and may lead to a higher incidence of ocular signs and symptoms, and poor compliance $[4,6-8]$. Benzalkonium chloride (BAK) is the most widely used preservative in IOP-lowering ophthalmic preparations. However, it has been demonstrated in a variety of experimental and clinical studies to be pro-apoptotic and pro-inflammatory, to damage tear film layer, corneal epithelium and corneal nerves, and has a negative impact on the number of conjunctival goblet cells [9-13]. Ocular surface disease (OSD) and dry eye syndrome 
are frequently detected in patients treated with preserved glaucoma medications [14, 15]. It has been shown that OSD is related to the number of preserved eye drops used, the prolonged use of preserved medication and the total benzalkonium chloride (BAK) exposure [13-16].

The use of preservative-free (PF) formulations may avoid these negative effects of BAK [17-19]. Tafluprost ophthalmic solution $0.0015 \%$ Taflotan $^{\mathrm{TM}}$, Saflutan ${ }^{\mathrm{TM}}$, Tapros $^{\mathrm{TM}}$, Santen, Osaka, Japan) was the first prostaglandin analog (PGA) that became available in a PF formulation. The IOPlowering efficacy of this $\mathrm{PF}$ formulation is comparable to that of latanoprost [20-22]. PGA/timolol FCs are frequently used in glaucoma management. Both active ingredients of these fixed combinations have a different mode of action [3]. These fixed combinations provide an IOP reduction of approximately $30-37 \%$ and have to be instilled only once daily [23, 24]. The additivity and safety of tafluprost and timolol administered in a non-fixed combination (NFC) have been demonstrated in two randomized, double-masked, parallel-group, multicenter clinical studies $[25,26]$. Thus, PF prostaglandin/timolol FC for the treatment of patients with glaucoma and ocular hypertension may have potential benefits for patients using fixed combinations of a prostaglandin analog and timolol.

The present study in patients with openangle glaucoma or ocular hypertension was designed to compare the IOP-lowering efficacy, safety and tolerability of the PF FC of tafluprost 0.0015\% (TAF)/timolol 0.5\% (TIM) ophthalmic solution to those of its individual components, namely, PF tafluprost $0.0015 \%$ and PF timolol $0.5 \%$.

\section{METHODS}

\section{Study Design}

This was a stratified, double-masked, randomized, multinational, multicenter phase III study conducted in 60 centers and 10 countries. The study was registered with ClinicalTrial.gov \#NCT01292460, and was reviewed and approved by the independent ethics committees of each participating country. Prior to enrollment, written informed consent was obtained from all patients. The study was conducted in accordance with the current good clinical practice (GCP) requirements. All procedures followed were in accordance with the ethical standards of the responsible committee on human experimentation (institutional and national), and with the Helsinki Declaration of 1975, as revised in 2000 and 2008. A power analysis was performed to justify the number of patients enrolled in the study.

\section{Study Population}

Male and female patients, aged 18 years and above, diagnosed with either ocular hypertension or open-angle glaucoma (primary open-angle, pseudoexfoliative or pigmentary glaucoma) in one or both eyes were enrolled in the study. All patients were required to be treated either with a PGA [prostaglandin stratum (PS)] or with timolol $0.5 \%$ (TIM) [timolol stratum (TS)] monotherapy for at least 2 weeks before the screening visit. To be eligible for study participation, the patients were required to have IOP in either treated eye of $\geq 22 \mathrm{mmHg}$ at any time of the day during the screening visit for prior timolol users (TS) or $\geq 20 \mathrm{mmHg}$ for prior prostaglandin analog 
users (PS). Other inclusion criteria were an increase of at least $2 \mathrm{mmHg}$ in the average diurnal IOP (measured at 8:00 a.m., 10:00 a.m., 4:00 p.m and 8:00 p.m.) at the baseline visit as compared to the average diurnal IOP at the endof-run-in period 2 weeks after the screening visit with either open-label timolol $0.5 \%$ (TS) or tafluprost $0.0015 \%$ (PS) treatment and a best corrected visual acuity no worse than +0.6 logarithm of the minimal angle of resolution ( $\log$ MAR) in both eyes. Exclusion criteria were pregnancy and planned pregnancy for the study period; nursing; corneal abnormalities or other conditions preventing reliable applanation tonometry; prior refractive eye surgery; hypersensitivity or contraindication to tafluprost or timolol; prior filtration surgery or any other ocular surgery including intraocular laser procedures within 6 months prior to screening in the eye(s) to be treated; advanced visual field defects in either eye or anticipated progression during the study period; risk for angle closure $(<2$ grade anterior chamber angle width according to Schaffer's classification); use of contact lenses at screening or during the study; and inability to safely discontinue the use of ocular hypotensive medications during the wash-out period.

\section{Study Visits and Treatment}

The study visits included screening, end-of-runin, baseline, 2 and 6 weeks, 3 and 6 months, and post-study (Fig. 1). At the screening visit, all eligible patients were assigned according to their prior treatment regimen [timolol $0.5 \%$ (TIM) or PGA] to receive either PF timolol $0.5 \%$ (TS) twice daily (8:00 a.m. and 8:00 p.m.) or PF tafluprost $0.0015 \%$ (PS) once daily (8:00 a.m.) for 2 weeks. The run-in period was followed by a wash-out period of at least 4 weeks. At the baseline visit, the TS patients were randomized to receive either PF timolol $0.5 \%$ twice daily (8:00 a.m. and 8:00 p.m.), or PF FC tafluprost 0.0015\%/timolol 0.5\% at 8:00 a.m. and vehicle at 8:00 p.m. in the affected eye(s). Accordingly, the PS patients were randomized to receive PF tafluprost $0.0015 \%$ once daily (8:00 a.m.) or PF tafluprost $0.0015 \% /$ timolol $0.5 \%$ FC once daily (8:00 a.m.) in the affected eye(s) (Fig. 2). Unilateral dosing of the study medication was also allowed when the contralateral eye required no treatment. All study medications were packed in identical single-dose containers and pouches for masking.

\section{Efficacy Variables}

Diurnal IOP measurements were made by calibrated Goldmann applanation tonometry at 8:00 a.m., 10:00 a.m., 4:00 p.m. and 8:00 p.m. during all visits other than screening and post-study; at these visits, a single IOP measurement was obtained at any time of the day. The primary evaluation of IOP was based on the worse eye and all patients who received at least one dose of the study medications and had at least one post-baseline measurement available [intention to treat (ITT) dataset]. If both eyes met the IOP criteria at baseline the eye with the higher IOP at the 8:00 a.m. IOP measurement was regarded as the worse eye. In case both eyes had the same IOP at baseline, the right eye was designated as the study eye. The primary efficacy variable was the change from baseline in the average diurnal IOP at month 3 . The primary statistical objective was to demonstrate that the PF FC tafluprost $0.0015 \% /$ timolol $0.5 \%$, administered once daily in the morning is superior to both individual components of the FC: PF tafluprost $0.0015 \%$ (TAF) administered once daily in the morning (8:00 a.m.) and PF timolol 0.5\% (TIM) administered twice daily (8:00 a.m. and 8:00 


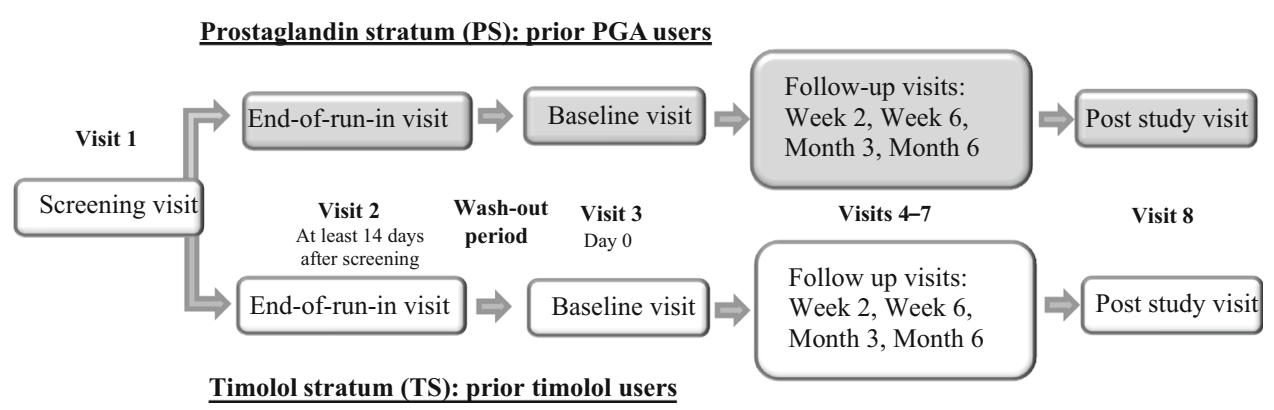

Fig. 1 An overview of scheduled study visits for both prostaglandin stratum and timolol stratum. $P G A$ prostaglandin analog, $P S$ prostaglandin stratum, $T S$ timolol stratum

p.m.). Secondary efficacy variables included the proportion of responders at month 3 (defined as change from baseline IOP of $20 \%$ or more in increments of 5\%), change from baseline in mean diurnal IOP at weeks 2 and 6 and month 6 , and change from baseline in the time-wise IOPs at 8:00 a.m., 10:00 a.m., 4:00 p.m., and 8:00 p.m. at weeks 2 and 6 and months 3 and 6 .

\section{Safety and Tolerability}

The analysis of the safety and tolerability data was based on all the patients who received at least one dose of the respective study medication and had a subsequent safety measurement. Ocular and non-ocular adverse events (AEs) were recorded at each visit. Slit lamp examinations were conducted at each visit and the findings were graded on a scale from 0 to 3 (0: normal; 1 : mild; 2 : moderate; 3 : severe). Central corneal thickness (CCT) was measured at screening and at month 6 by ultrasound pachymetry. The severity of conjunctival hyperemia was assessed from baseline through month 6 using a set of reference photographs (redness grading) and a 5-point scale (0: none; 1 : mild; 2 : moderate; 3 : severe; 4: very severe). Ophthalmoscopic examinations were conducted via dilated pupil at screening and at months 3 and 6 , and included the evaluation of vitreous, retina, and optic nerve head. Visual field testing was performed at screening and post-study. Drop discomfort was evaluated at weeks 2 and 6 and months 3 and 6 on a 4-point scale (0: none, 1 : mild, 2: moderate, 3: severe). Resting blood pressure and heart rate were measured twice during the day at 8:00 a.m. and 10:00 a.m. from baseline visit to month 6 .

\section{Statistical Methods}

A repeated-measures analysis of the covariance (RM ANCOVA) model was used to evaluate the primary efficacy variable within the TS and PS. A two-sided 95\% confidence interval (CI) for the mean difference estimated from the model was used for the evaluation of the superiority hypothesis. Superiority was achieved if the upper limit of the 95\% CI (TS: FC-TIM; PS: FC-TAF) was less than $0 \mathrm{mmHg}$ or the corresponding $p$ value was less than 0.05 . The last observation carried forward (LOCF) method was used for discontinued patients in the ITT dataset at month 3. A Cochran-MantelHaenszel $(\mathrm{CMH})$ test was used for the comparison of non-continuous variables between the two treatment groups. The planned sample size was 220 enrolled subjects (110 per arm) in the TS and 380 enrolled subjects (190 per arm) in the PS. These sample 
sizes provided the power of $90 \%$ based on differences of $2.0 \mathrm{mmHg}$ for the TS and $1.5 \mathrm{~mm} \mathrm{Hg}$ for the PS, a standard deviation (SD) of $4.0 \mathrm{mmHg}$ for change in IOP, a drop-out rate of $20 \%$ and a two-sided $5 \%$ type I error. A smaller drop-out rate than anticipated was seen during the study, thus fewer patients could be randomized in the study without a loss in statistical power.

\section{RESULTS}

In total, 711 subjects were screened for the study. Of these, 564 patients with open or ocular hypertension who met the inclusion criteria were enrolled: 189 patients were randomized and treated in the TS $(n=95$ patients in the FC arm and $n=94$ in the TIM arm) and another 375 patients were randomized and treated in the PS ( $n=188$ patients in the FC arm and 187 patients in the TAF arm) (Fig. 2).

The treatment arms within both strata were comparable with regard to demographic characteristics and baseline IOP: the majority of patients were female and the mean age was $65.7 \pm 10.27$ years. Primary open-angle glaucoma was the most frequent diagnosis (73.9\%), followed by ocular hypertension (22.3\%), pseudoexfoliative glaucoma (2.8\%) and pigmentary glaucoma $(0.9 \%)$. In the TS and PS, mean baseline IOPs were similar for both arms at all time points (8:00 a.m., 10:00 a.m., 4:00 p.m. and 8:00 p.m.), and ranged between 25.9 and $26.9 \mathrm{mmHg}$ in the TS and 25.5 and $26.6 \mathrm{mmHg}$ in the PS, respectively (Table 1).

A total of 172 patients (91.0\%) completed the 6-month study period in the TS: 86 patients (FC 90.5\%; TIM 91.5\%) in both treatment arms. The most common primary reasons for termination in the TS were: patient request (3 patients for both FC and TIM), AEs (5 patients for FC and 1 patient for TIM) and uncontrolled IOP ( 1 patient for FC and 2 patients for TIM). In the PS, a total of 348 patients (92.8\%) completed the 6-month study period: 175

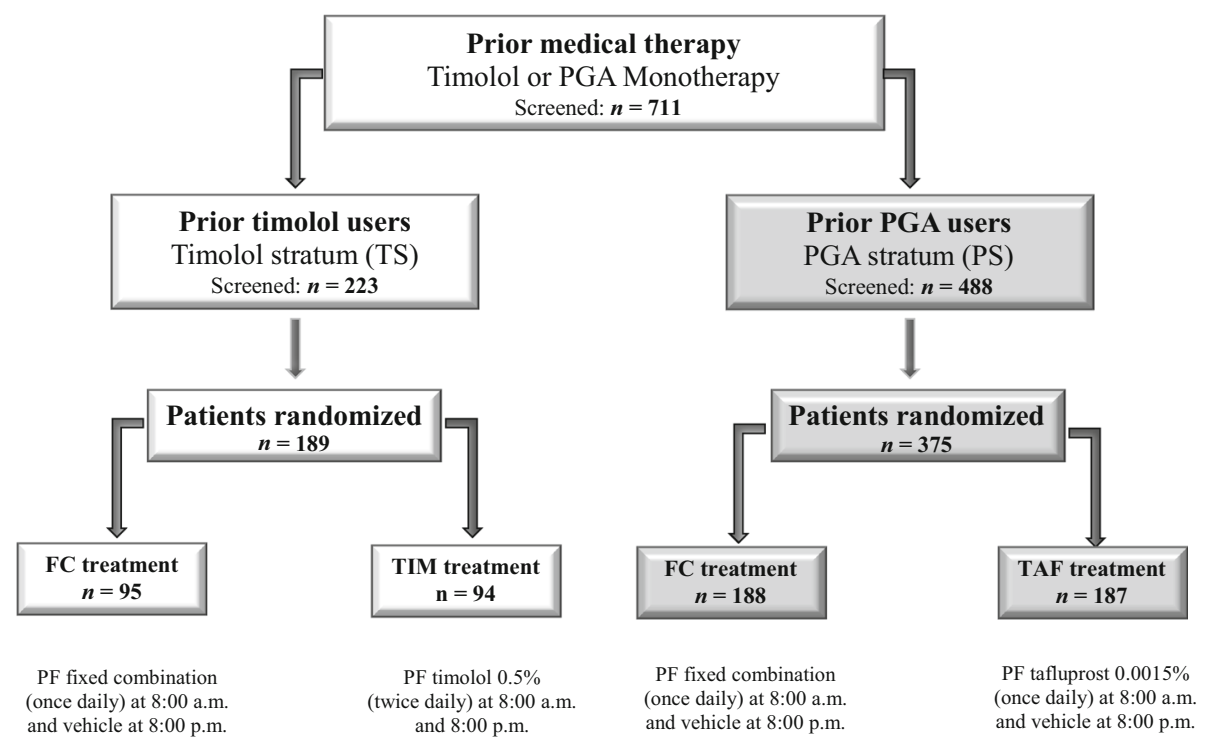

Fig. 2 Stratification, number of patients, and medical treatment. $F C$ preservative-free fixed combination tafluprost $0.0015 \% /$ timolol $0.5 \%$. PGA prostaglandin

analog, PS prostaglandin stratum, TAF monotherapy preservative-free tafluprost $0.0015 \%$, TIM monotherapy preservative-free timolol $0.5 \%, T S$ timolol stratum 
Table 1 Demographic and baseline characteristics by treatment group

\begin{tabular}{|c|c|c|c|c|c|c|c|c|c|}
\hline & \multicolumn{4}{|c|}{ Timolol stratum (TS) } & \multicolumn{5}{|c|}{ Prostaglandin stratum (PS) } \\
\hline & \multicolumn{2}{|c|}{$\overline{\mathrm{FC}}(n=95)$} & \multicolumn{2}{|c|}{ TIM $(n=94)$} & \multicolumn{3}{|c|}{$\mathrm{FC}(n=188)$} & \multicolumn{2}{|c|}{ TAF $(n=187)$} \\
\hline \multicolumn{10}{|l|}{ Gender, $n(\%)$} \\
\hline Male & \multicolumn{2}{|l|}{$44(46.3)$} & \multicolumn{2}{|l|}{$36(38.3)$} & \multicolumn{3}{|l|}{$70(37.2)$} & \multicolumn{2}{|l|}{$61(32.6)$} \\
\hline Female & \multicolumn{2}{|l|}{$51(53.7)$} & \multicolumn{2}{|l|}{$58(61.7)$} & \multicolumn{3}{|l|}{$118(62.8)$} & \multicolumn{2}{|l|}{$126(67.4)$} \\
\hline \multicolumn{10}{|l|}{ Age (years) } \\
\hline Mean & \multicolumn{2}{|l|}{64.9} & \multicolumn{2}{|l|}{67.4} & \multicolumn{3}{|l|}{65.4} & \multicolumn{2}{|l|}{65.4} \\
\hline SD & \multicolumn{2}{|l|}{10.3} & \multicolumn{2}{|l|}{9.2} & \multicolumn{3}{|l|}{10.7} & \multicolumn{2}{|l|}{10.3} \\
\hline Range & \multicolumn{2}{|l|}{$23-84$} & \multicolumn{2}{|l|}{$40-87$} & \multicolumn{3}{|l|}{$27-85$} & \multicolumn{2}{|l|}{$25-87$} \\
\hline Central corneal thickness $(\mu \mathrm{m})$ & Right & Left & Right & Left & Right & Left & & Right & Left \\
\hline Mean & 555 & 556 & 554 & 554 & 542 & 541 & & 544 & 544 \\
\hline SD & 36.1 & 37.4 & 39.6 & 43.0 & 33.6 & 33.6 & & 34.7 & 35.7 \\
\hline Range & $460-659$ & $475-665$ & $337-640$ & $282-631$ & $442-646$ & 437 & -635 & $445-648$ & $448-637$ \\
\hline \multicolumn{10}{|l|}{ Ocular diagnosis, worse eye $n(\%)$} \\
\hline Ocular hypertension & \multicolumn{2}{|l|}{$25(26.3)$} & \multicolumn{2}{|l|}{$23(24.5)$} & \multicolumn{3}{|l|}{$39(20.7)$} & \multicolumn{2}{|l|}{$39(20.9)$} \\
\hline Primary open-angle glaucoma & $69(72.6)$ & & $69(73.4)$ & & $140(74.5)$ & & & $139(74.3)$ & \\
\hline Pseudoexfoliative glaucoma & $0(0.0)$ & & $2(2.1)$ & & $7(3.7)$ & & & $7(3.7)$ & \\
\hline Pigmentary glaucoma & $1(1.1)$ & & $0(0.0)$ & & $2(1.1)$ & & & $2(1.1)$ & \\
\hline Baseline intraocular pressure, $\mathrm{mn}$ & $\mathrm{nHg}$ (mean & $\pm \mathrm{SD}) \mathrm{IT}$ & $T$ dataset & & & & & & \\
\hline 8:00 a.m. & $26.94(2.8$ & & 26.55 & & 26.35 & & 26.5 & $(3.21)$ & \\
\hline 10:00 a.m. & 26.50 & & 26.32 & & 25.93 & & 26.10 & $(3.01)$ & \\
\hline 4:00 p.m. & $26.32(2.0$ & & $25.97(2.3$ & & $25.63(3.17$ & & 25.5 & $(3.13)$ & \\
\hline 8:00 p.m. & 26.19 & & 25.87 & & 25.54 & & 25.6 & $(2.74)$ & \\
\hline
\end{tabular}

$F C$ preservative-free fixed combination tafluprost $0.0015 \% /$ timolol $0.5 \%, I T T$ intention to treat, $S D$ standard deviation, $T A F$ monotherapy preservative-free tafluprost $0.0015 \%$, TIM monotherapy preservative-free timolol $0.5 \%$

patients $(93.1 \%)$ in the FC arm and 173 patients $(92.5 \%)$ in the TAF arm. The most common primary reasons for termination in the PS were: uncontrolled IOP (5 patients for FC and 8 patients for TAF), AEs ( 6 patients for FC and 2 patients for TAF) and patient request ( 2 patients for FC and 3 patients for TAF).

Only 3 patients had no post-baseline efficacy data; thus, the ITT datasets included 188 and
373 patients in the TS and PS, respectively: in the TS, 95 patients treated with the FC and 93 treated with TIM, in the PS 188 patients treated with FC and 185 patients treated with TAF.

\section{Efficacy in Prior Timolol Users (TS)}

A clinically and statistically significant reduction of IOP from baseline was seen with 
Table 2 Overall treatment differences in IOP at month 3 (ITT LOCF dataset)-TS and PS. For the TS, the effect of the outlier is shown separately

\begin{tabular}{llll}
\hline $\begin{array}{l}\text { RM ANCOVA ITT } \\
\text { dataset (month 3) }\end{array}$ & $\begin{array}{l}\text { PF FC versus monotherapy PF } \\
\text { TIM (primary with outlier) }\end{array}$ & $\begin{array}{l}\text { PF FC versus monotherapy PF } \\
\text { TIM (without outlier) }\end{array}$ & $\begin{array}{l}\text { PF FC versus } \\
\text { monotherapy PF } \\
\text { TAF }\end{array}$ \\
\hline Difference (mmHg) & -0.885 & -1.136 & -1.516 \\
Upper 95\% CI & -0.024 & -0.379 & -0.988 \\
Lower 95\% CI & -1.745 & -1.897 & -2.044 \\
$p$ value & 0.044 & 0.004 & $<0.001$ \\
\hline
\end{tabular}

$C I$ confidence interval, $F C$ preservative-free fixed combination tafluprost $0.0015 \% /$ timolol $0.5 \%, I O P$ intraocular pressure, $I T T$ intention to treat, $L O C F$ last observation carried forward, $P F$ preservative free, $P S$ prostaglandin stratum, $R M$ ANCOVA repeat measures analysis of the covariance, TAF monotherapy preservative-free tafluprost $0.0015 \%$, TIM monotherapy preservative-free timolol $0.5 \%, T S$ timolol stratum

both treatment regimens throughout the study, and low IOP levels were maintained in both treatment arms up to the 6-month visit. Timewise differences at all visits were clearly in favor of the FC: FC lowered IOP between 7.1 and $9.0 \mathrm{mmHg}$ (within group $p<0.001$ at all time points, ITT dataset). In comparison, TIM $0.5 \%$ twice daily lowered IOP between 6.5 and $8.1 \mathrm{mmHg}$ (within group $p<0.001$ at all time points, ITT dataset) (Fig. 3). At month 3, the time-wise differences (FC-TIM) ranged on average from -1.50 to $-0.85 \mathrm{mmHg}$ (Fig. 4), and the estimated average treatment difference (FC-TIM) from the primary RM ANCOVA model for the ITT LOCF dataset was $-0.885 \mathrm{mmHg}$ with a $95 \%$ CI from -1.745 to $-0.024 \mathrm{mmHg}$ $(p=0.044)$, thus superiority of FC over TIM was achieved (Table 2). The sensitivity analysis without using the baseline IOP as a covariate (RM ANOVA) confirmed these results: the treatment difference at month 3 was $-1.105 \mathrm{mmHg}$ with a $95 \% \mathrm{CI}$ from -1.995 to $-0.215 \mathrm{mmHg}(p=0.015)$. IOP levels for all individual patients in the TS at baseline and at month 3 and the corresponding box-whisker plots of mean diurnal IOPs (mmHg) at month 3 versus baseline are shown in Fig. 5. It should be noted that one outlier had a substantial effect on the result (Fig. 5a).

The results for all secondary efficacy variables were well in line with the primary efficacy variable: the proportion of responders (reduction of mean IOP of 20, 25, 30, and 35\%) was in favor of the FC in each response category. A decrease of $35 \%$ or more was seen in $33.7 \%$ in the FC treatment arm and $23.7 \%$ in the TIM treatment arm ( $p=0.081$; CMH-test; ITT LOCF dataset). It should be noted that TS was not properly powered for responder analyses. Furthermore, all estimated time-wise treatment differences (FC-TIM) were clearly in favor of the FC and on average around $1 \mathrm{mmHg}$; the favorable average difference was sustained up to month 6 ( $p=0.017$; RM ANCOVA; ITT dataset).

\section{Efficacy in Prior PGA users (PS)}

A clinically and statistically significant reduction of IOP from baseline was seen with both treatment regimens throughout the study, and low IOP levels were maintained in both treatment arms up to 6 months. Time-wise differences at all visits were clearly in favor of the FC: FC lowered IOP between 8.2 and 


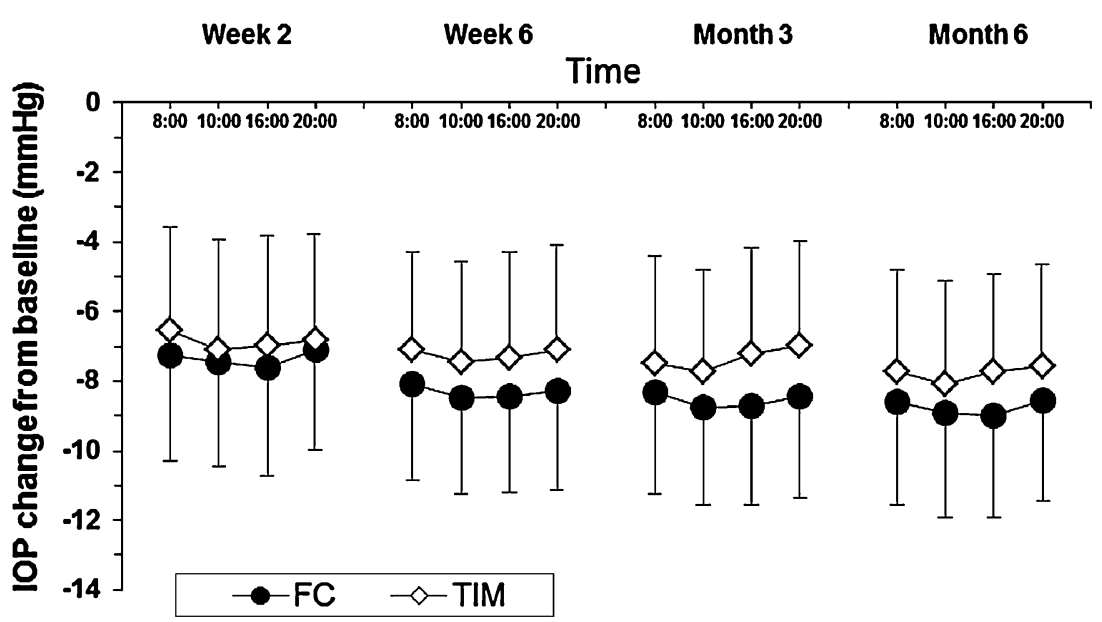

Fig. 3 Changes of mean (SD) intraocular pressure (IOP) from baseline at weeks 2 and 6 , and months 3 and 6 at 8 a.m., 10 a.m., 4 p.m. and 8 p.m. in the TS. Worse eye analysis in the ITT dataset. $F C$ preservative-free fixed

$9.0 \mathrm{mmHg}$ (within group $p<0.001$ at all time points, ITT dataset). In comparison, TAF lowered IOP between 6.8 and $7.4 \mathrm{mmHg}$ (within group $p<0.001$ at all time points, ITT dataset) (Fig. 6). At month 3, the time-wise differences (FC-TAF) ranged on average from -1.76 to $-1.03 \mathrm{mmHg}$ (Fig. 4) and the estimated average treatment difference (FCTAF) from the primary RM ANCOVA model for the ITT LOCF dataset was $-1.516 \mathrm{mmHg}$ with a $95 \%$ CI from -2.044 to $-0.988 \mathrm{mmHg}$ $(p<0.001)$, thus the superiority of FC over TAF was achieved (Table 2). The sensitivity analysis without the baseline covariate (RM ANOVA) confirmed these results: the treatment difference at month 3 was $-1.402 \mathrm{mmHg}$ with a $95 \%$ CI from -1.996 to $-0.807 \mathrm{mmHg}$ $(p<0.001)$. IOP levels for all individual patients in the PS at baseline and at month 3 and the corresponding box-whisker plots of mean diurnal IOPs (mmHg) at month 3 versus baseline are shown in Fig. 7.

The results for all secondary efficacy variables were well in line with the primary combination tafluprost $0.0015 \% /$ timolol $0.5 \%, \quad I O P$ intraocular pressure, $I T T$ intention to treat, $S D$ standard deviation, TIM monotherapy preservative-free timolol $0.5 \%$, TS timolol stratum

efficacy variable. The proportion of responders (reduction of mean IOP of 20, 25, 30, and 35\%) was in favor of the FC: in each response category, there was a clear and statistically significant advantage in favor of the FC. IOP reductions of $\geq 30 \%$ from baseline were achieved in $61.8 \%$ and $37.9 \%$ of patients in the FC and TAF treatment arm, respectively ( $p<0.001 ;$ CMH-test; ITT LOCF dataset), and IOP reductions of $\geq 35 \%$ from baseline was achieved in $38.2 \%$ and $23.6 \%$ of patients in the FC and TAF treatment arm, respectively ( $p=0.002$; CMH-test; ITT LOCF dataset.

Furthermore, all estimated time-wise treatment differences (FC-TAF) were clearly in favor of the $\mathrm{FC}$, on average around $1.5 \mathrm{mmHg}$, and the favorable average difference was sustained up to 6 months $(p<0.001 ; \mathrm{RM}$ ANCOVA; ITT dataset).

\section{Ocular and Non-ocular Adverse Events}

In the TS, 94 related and non-related AEs (54 ocular, 40 non-ocular) were reported by 43 


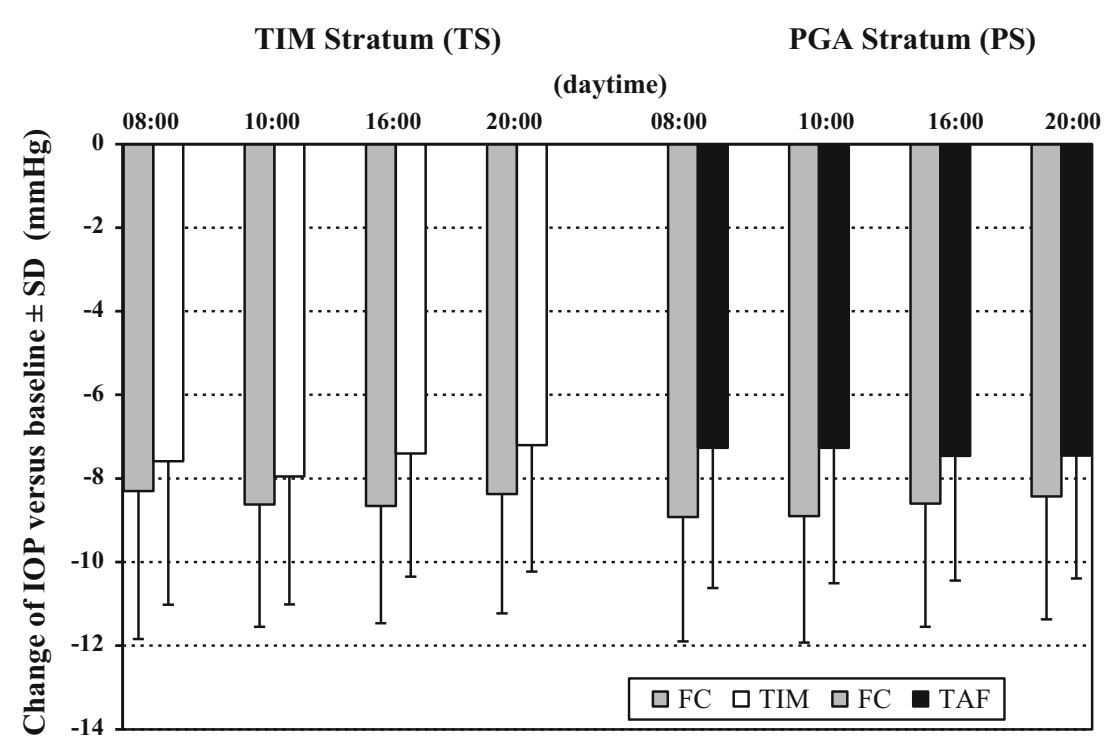

Fig. 4 Changes of mean (SD) intraocular pressure (IOP) from baseline at month 3 for both strata by treatment group at 8 a.m., 10 a.m., 4 p.m., and 8 p.m.. Worse eye analysis in the ITT dataset. $F C$ preservative-free fixed combination tafluprost $0.0015 \% /$ timolol $0.5 \%, \quad I O P$ intraocular pressure, ITT intention to treat, $P G A$ prostaglandin analog, $P S$ prostaglandin stratum, $S D$ standard deviation, $T A F$ monotherapy preservative-free tafluprost $0.0015 \%$, TIM monotherapy preservative-free timolol $0.5 \%$, TS timolol stratum (a)

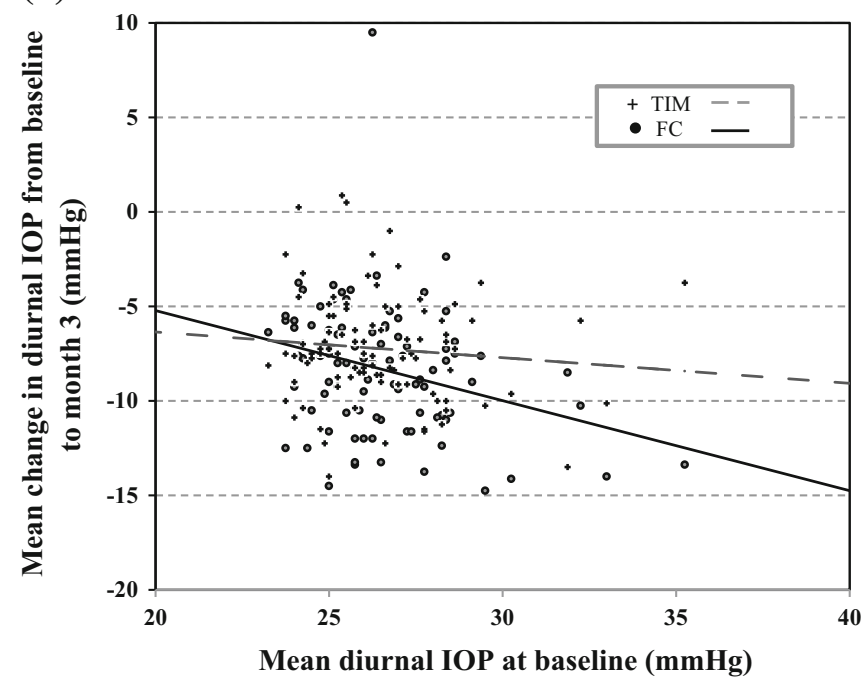

Fig. 5 a Scatterplot of mean change in diurnal IOPs $(\mathrm{mmHg})$ from baseline to month 3 in the TS and b corresponding box-whisker plot of mean diurnal IOPs $(\mathrm{mmHg})$ at month 3 versus baseline for FC and TIM. FC

patients $(45.3 \%)$ in the FC treatment arm and 89 AEs (15 ocular, 74 non-ocular) were reported by 35 patients $(37.2 \%)$ in the TIM treatment (b)

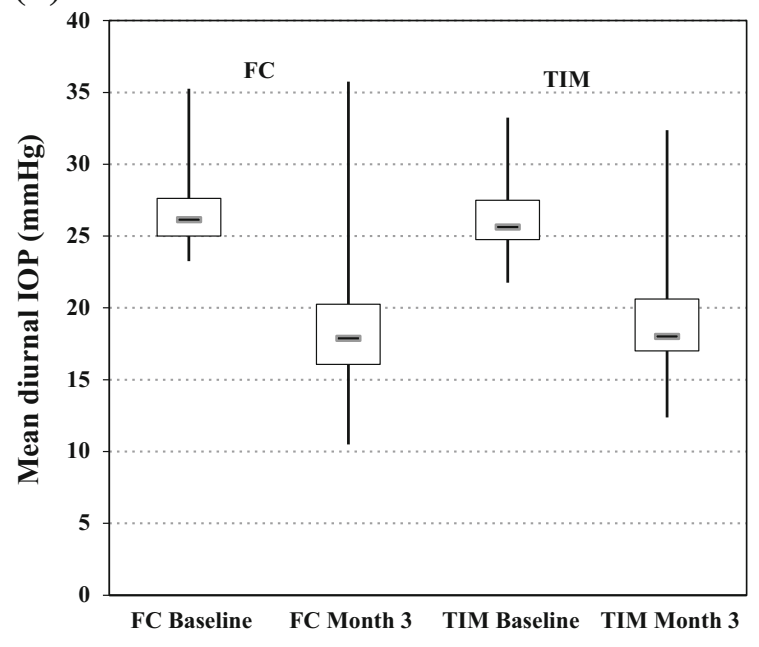

preservative-free fixed combination tafluprost $0.0015 \%$ / timolol $0.5 \%$, IOP intraocular pressure, TIM monotherapy preservative-free timolol $0.5 \%$, TS timolol stratum

arm. Overall, there were fewer ocular AEs, but more non-ocular AEs in the TIM treatment arm compared to FC. In total, 7 patients (5 in the FC 


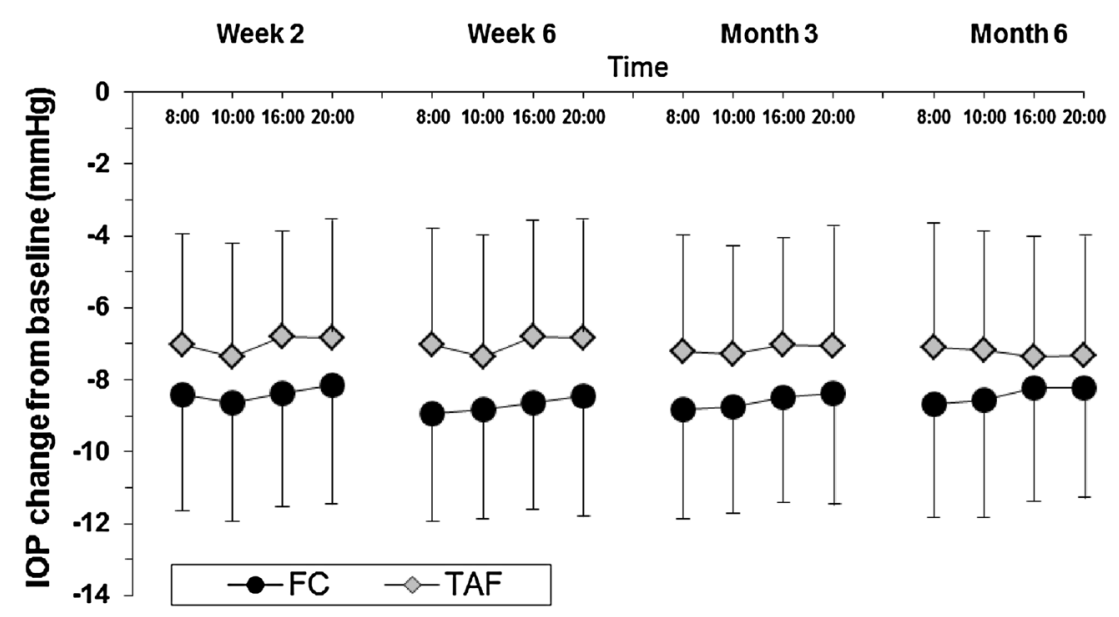

Fig. 6 Changes of mean (SD) intraocular pressure from baseline at weeks 2 and 6 and months 3 and 6 at 8 a.m., 10 a.m., 4 p.m. and 8 p.m. in the prostaglandin stratum (PS). Worse eye analysis in the ITT dataset. $F C$ preservative-free

and 2 in the TIM treatment arm) discontinued the study due to AEs in the TS. Treatmentrelated AEs leading to study termination of 4 patients in the TS were ocular in all cases in the FC treatment arm. These included: erythema of the eyelid, eyelid pain, ocular discomfort, conjunctival/ocular hyperemia, photophobia, blepharitis, madarosis, meibomianitis and eye pruritus. Both terminations in the TIM treatment arm were due to AEs which were not treatment related. In the PS, 219 AEs (94 ocular, 125 non-ocular) were reported by 84 patients $(44.7 \%)$ in the FC treatment arm and 136 AEs (70 ocular, 66 non-ocular) were reported by 71 patients $(38.0 \%)$ in the TAF treatment arm. In total, 8 patients (6 in the FC and 2 in the TAF treatment arm) discontinued the study due to AEs in the PS. Treatmentrelated AEs leading to study termination in the PS were ocular in most cases in the FC treatment arm and included: erythema, eye irritation, blurred vision, conjunctival/ocular hyperemia, eye pain, eye pruritus and increased lacrimation. All terminations in the TAF treatment arm were related to ocular AEs: conjunctival hyperemia, conjunctival edema, fixed combination tafluprost $0.0015 \% /$ timolol $0.5 \%$, $I O P$ intraocular pressure, ITT Intention to treat, $T A F$ monotherapy preservative-free tafluprost $0.0015 \%, S D$ standard deviation

erythema of the eyelid, eyelid edema, IOP increase and blurred vision.

The most frequent ocular AEs (reported for more than 2 patients) are summarized in Table 3 for both strata. Most of the ocular AEs were graded as mild. Conjunctival/ocular hyperemia was the most frequent treatmentrelated $\mathrm{AE}$ in both strata. In the TS, treatmentrelated hyperemia was reported in 9 patients (9.5\%) in the FC arm and for none in the TIM treatment arm. The evaluation of conjunctival redness in patients in the TIM arm also showed lower levels of redness, and a lower proportion of patients with low or no redness grading (Fig. 8a). In the PS, treatment-related hyperemia was reported in 9 patients $(4.8 \%)$ in the FC arm and 6 patients (3.2\%) in the TAF arm. In general, the severity of hyperemia was mild to moderate. In both strata, the mean severity of conjunctival hyperemia, evaluated by reference photographs, was highest at week 2 and showed a decreasing tendency during the course of the study (Fig. $8 a$ and b). There were no signs of treatment-related adverse events of the inner eye optical media and fundus or visual fields. No significant changes 
(a)

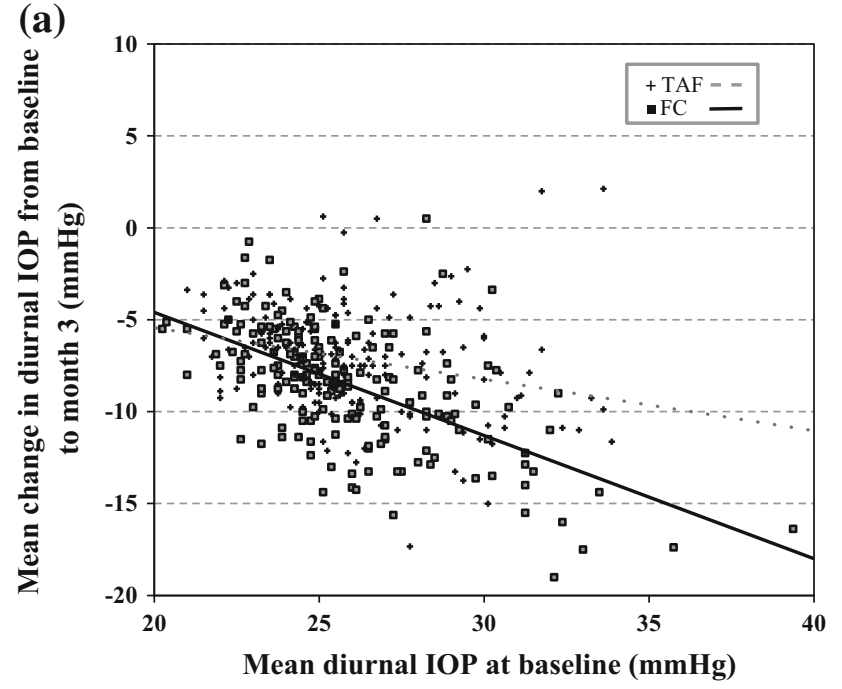

Fig. 7 a Scatterplot of mean change in diurnal IOPs $(\mathrm{mmHg})$ from baseline to month 3 in the PS and b corresponding box-whisker plot of mean diurnal IOPs $(\mathrm{mmHg})$ at month 3 versus baseline for FC and TAF. FC

of visual fields were revealed post-study in comparison to the screening visit. All treatment regimens were generally well tolerated with approximately $70-80 \%$ of patients experiencing no drop discomfort upon instillation during the study. Most discomfort cases were experienced at week 2 in both strata and treatment arms: In the TS, 27 patients (30.0\%) reported discomfort (23 mild, 3 moderate and 1 severe) in the FC arm and 28 patients $(30.4 \%)$ in the TIM arm (22 mild, 6 moderate). In the PS at week 2, 49 patients (26.2\%) reported discomfort (42 mild, 7 moderate) in the FC arm and 41 patients (22.4\%) in the TAF arm (34 mild, 7 moderate). No statistically significant differences in the drop discomfort were seen in any of the time points in either stratum.

\section{DISCUSSION}

Fixed combinations of PGAs and timolol are widely used in glaucoma management because (b)

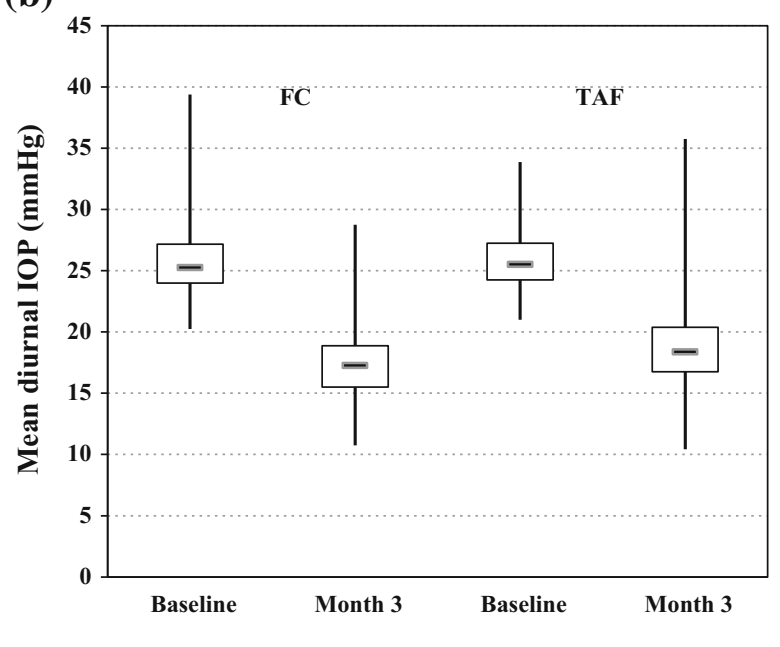

preservative-free fixed combination tafluprost 0.0015\%/ timolol $0.5 \%, I O P$ intraocular pressure, TAF monotherapy preservative-free tafluprost $0.0015 \%, P S$ prostaglandin stratum

they offer several advantages; most of all, the use of one bottle compared to the concomitant use of the individual components increases patient convenience. Frequent dosing is related to poor adherence, thus a simplified dosing regimen of fixed combinations is likely to lead to an improvement in patients' adherence [27]. Furthermore, fixed combinations eliminate the risk of a wash-out effect caused by the instillation of a second eye drop after a too-short interval within a concomitant treatment regimen. Finally, the use of fixed combinations decreases, but does not eliminate the exposure of the eye to preservatives. There is strong evidence from both clinical and animal studies that chronic exposure to preservatives, particularly BAK, induces ocular surface changes, conjunctival inflammation, subconjunctival fibrosis, apoptosis of conjunctival epithelial cells and corneal surface changes $[6,9,11,13]$. Moreover, OSD and dry eye syndrome are very common in glaucoma patients: several studies report 
Table 3 Most frequent treatment-related ocular adverse events (number of patients)

\begin{tabular}{|c|c|c|c|c|}
\hline \multirow[t]{2}{*}{ Ocular adverse events } & \multicolumn{2}{|c|}{ TIM stratum (TS) } & \multicolumn{2}{|c|}{ PGA stratum (PS) } \\
\hline & $\overline{\text { FC }(n=95)}$ & TIM $(n=94)$ & $\overline{\text { FC }(n=188)}$ & TAF $(n=187)$ \\
\hline Conjunctival hyperemia ${ }^{a}$ & 4 & 0 & 5 & 3 \\
\hline Dry eye & 2 & 1 & 0 & 3 \\
\hline Eye irritation & 2 & 3 & 5 & 0 \\
\hline Eye pain & 2 & 2 & 7 & 6 \\
\hline Eye pruritus & 4 & 0 & 6 & 3 \\
\hline Eyelid edema & 0 & 0 & 0 & 4 \\
\hline Foreign body sensation & 3 & 0 & 3 & 2 \\
\hline Ocular discomfort & 2 & 0 & 0 & 0 \\
\hline Ocular hyperemia $^{a}$ & 5 & 0 & 4 & 3 \\
\hline Vision blurred & 2 & 1 & 3 & 4 \\
\hline Eyelid erythema & 0 & 0 & 1 & 2 \\
\hline Eyelash growth & 0 & 0 & 2 & 2 \\
\hline Eyelash discolouration & 0 & 0 & 1 & 1 \\
\hline Eyelash thickening & 0 & 0 & 1 & 1 \\
\hline Photophobia & 0 & 0 & 1 & 1 \\
\hline
\end{tabular}

$F C$ preservative-free fixed combination tafluprost $0.0015 \% /$ timolol $0.5 \%, P G A$ prostaglandin analog, TAF monotherapy preservative-free tafluprost $0.0015 \%$, TIM monotherapy preservative-free timolol $0.5 \%$

a The terms "conjunctival hyperemia" and "ocular hyperemia" were used in parallel. Adverse events for this category were counted only once for each patient

prevalence rates between 45 and $60 \%[14,15$, 28]. Preservative-free glaucoma medications are generally better tolerated than preserved eye drops $[18,19]$.

In the present study, we evaluated and compared the IOP-lowering efficacy, safety and tolerability of the PF FC of tafluprost $0.0015 \%$ and timolol $0.5 \%$ (administered once daily in the morning) to the individual PF components tafluprost $0.0015 \%$ (administered once daily in the morning) and timolol $0.5 \%$ (administered twice daily). It is well established that both PF tafluprost and timolol effectively reduce IOP as monotherapy $[20,21,29,30]$, are additive in IOP reduction in concomitant use [25] and neither of these two substances requires BAK to enhance its IOP-lowering activity [20-22, 30-32].

The results of this stratified, double-masked, randomized, multinational, multicenter phase III study demonstrate that PF FC tafluprost 0.0015\%/timolol $0.5 \%$ administered once daily significantly lowered IOP in each stratum, at each visit and time point during the 6-month study period. The IOP reduction in the FC treatment arms of both strata (PS and TS) was comparable. Mean time-wise IOP reductions from the corresponding diurnal baseline IOP levels in the TS ranged between 7.1 and $9.0 \mathrm{mmHg} \quad(26.7-34.1 \%)$ and 8.2 and $9.0 \mathrm{mmHg}(31.2-33.5 \%)$ in the PS. These changes are clinically significant and in a 


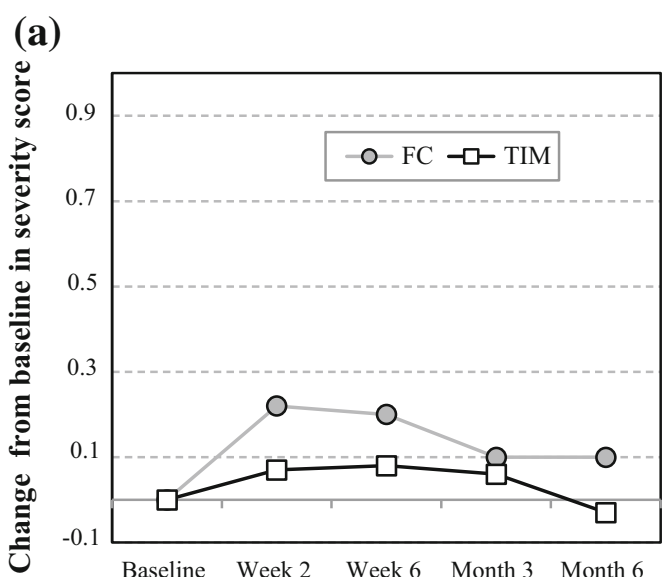

Fig. 8 Change of conjunctival hyperemia expressed as the mean value of the largest change from baseline in severity score values (scored between 0 and 4 in 0.5 increments) for (a) timolol stratum and (b) prostaglandin stratum. FC

comparable range to those found for other preserved prostaglandin/timolol fixed combinations: Mean diurnal IOP decrease from baseline with a preserved fixed combination of latanoprost/timolol was $8.0 \mathrm{mmHg}$ after 13 weeks with untreated baseline IOP levels that were comparable to the present study [33]. However, in this study design patients were treated with timolol $0.5 \%$ twice daily during a 2-week run-in period. In a study comparing a preserved fixed combination of bimatoprost/timolol with the individual components, mean diurnal IOP was decreased by $8.1 \mathrm{mmHg}$ in the fixed combination treatment arm [34]. The proportion of patients achieving a reduction of mean diurnal IOP of $\geq 20 \%$ from baseline was $81.8 \%$, which compares to $85.9 \%$ and $89.2 \%$ in this study for the TS and PS, respectively. Finally, a preserved fixed combination of travoprost/timolol reduced mean diurnal IOP from untreated diurnal baseline IOP levels between 27.2 and $30.2 \mathrm{mmHg}$ to IOP levels between 18.7 and $18.2 \mathrm{mmHg}$ at month 3 [35]. (b)

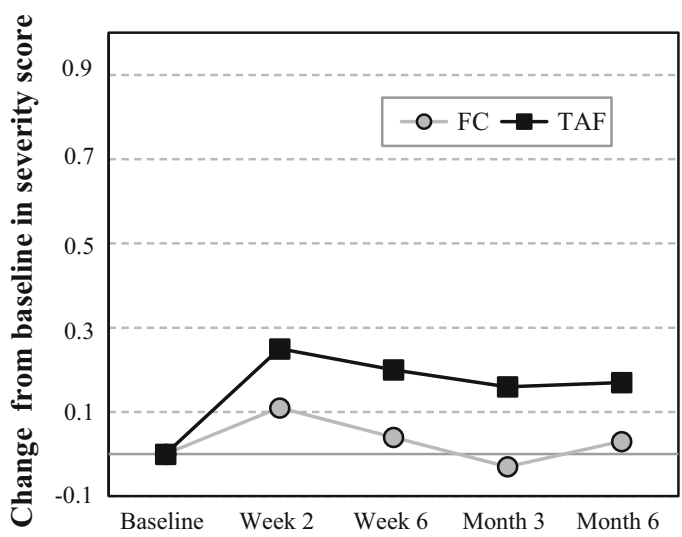

preservative-free fixed combination tafluprost $0.0015 \%$ / timolol $0.5 \%$, TAF monotherapy preservative-free tafluprost $0.0015 \%$, TIM monotherapy preservative-free timolol $0.5 \%$

The reduction of IOP in the FC treatment arms was superior to both individual components administered as monotherapy (PF TIM and PF $\mathrm{TAF})$. In the TS of the present study, the modelbased difference in IOP at month 3 (ITT LOCF dataset) between treatment arms (FC-TIM) was $-0.885 \mathrm{mmHg} \quad(95 \% \quad \mathrm{CI}$ from -1.745 to $-0.024 \mathrm{mmHg} ; p=0.044)$; thus the superiority of FC versus TIM was achieved. The analysis of sensitivity without the baseline values as covariate (RM ANOVA) confirmed this finding.

It should also be noted that one outlier in the FC treatment arm had a substantial effect on the result. This patient was discontinued after 14 days and the IOP of the unscheduled withdrawal visit was carried forward in the ITT dataset until month 3 according to the LOCF method. After discarding this patient (with data only from discontinuation visit after 14 days) from the ITT LOCF dataset, the difference was $-1.138 \mathrm{mmHg}$ (95\% CI from -1.897 to $-0.379 \mathrm{mmHg} ; p=0.004)$ in the primary RM ANCOVA model (Fig. 5; Table 2). Although this outlier was not removed from the overall 
analysis, it should be noted that it clearly influences the overall result (Table 2) and brings forth the conservative nature of the LOCF analyses. It might further be considered that timolol has less efficacy than FC over a complete period of $24 \mathrm{~h}$ including night time IOP measurements due to reduced efficacy of timolol during the night [36]. On the other hand, tafluprost monotherapy and the FC may appear better when a complete 24 -h period is considered.

In the PS, the difference in IOP at month 3 (ITT LOCF) between treatment arms (FC-TAF) was $-1.516 \mathrm{mmHg}$ (95\% CI -2.044 to -0.988 ; $p<0.001)$; thus superiority of FC versus TAF was achieved. The sensitivity analysis without the baseline values as covariate (RM ANOVA) confirmed these results. In the present study, the tafluprost/timolol FC was administered at 8:00 a.m. in the morning. In the PS, TAF was also instilled at 8:00 a.m., which allowed a fair comparison of the IOP-lowering effect of both treatment arms. Furthermore, timolol 0.5\% was dosed twice daily in the TS. In general the evening administration had been slightly favoring the efficacy of prostaglandin analogs [23]. In a study conducted by Konstas [37], morning versus evening dosing of a concomitant treatment of latanoprost $0.005 \%$ / timolol $0.5 \%$ instilled once daily was compared. Overall, a trend for greater daytime IOP reduction with evening dosing was found, whereas morning dosing tended to provide lower night time pressures [37]. Furthermore, it could be shown for fixed combinations of travoprost and timolol, and bimatoprost and timolol, that evening dosing provided a better 24-h IOP control when compared to morning dosing [38, 39].

The safety profile of the PF FC of tafluprost $0.0015 \%$ and timolol $0.5 \%$ was well in line with the known side effects of timolol and tafluprost.
Specifically, the hyperemia rates of the FC were very low in both strata: $4.8 \%$ and $9.5 \%$ for the PS and TS, respectively, and $6.4 \%$ over the two strata. The reason for the lower hyperemia rate in the PS compared to the TS may most likely be explained by the previous exposure of these patients to prostaglandin therapies. In turn, conjunctival hyperemia was reported for $22.7 \%$ of the patients at month 3 in the bimatoprost/ timolol fixed combination study [34]. Accordingly, hyperemia was reported for $14.1 \%$ of the patients treated with travoprost/ timolol preserved fixed combination [35]. These rates are considerably higher than those seen in the present study and suggest that the PF tafluprost/timolol FC may be better tolerated and an important treatment option for all patients who require an effective and safe combination therapy in clinical practice.

Despite the prospective, multicenter, randomized, double-masked design and the large number of patients in each stratum, our study has limitations. The tafluprost/timolol FC was administered in the morning. Therefore, we could not evaluate the potential efficacy differences between this regimen and the evening administration of the FC. A direct comparison of the morning versus evening dosing of the PF FC of tafluprost $0.0015 \% /$ timolol $0.5 \%$ may be needed to reveal possible efficacy differences of the 2 different dosing regimens after instillation of the new PF FC.

\section{CONCLUSION}

In conclusion, our multicenter, randomized, double-masked parallel-group study shows that once daily morning instillation of PF tafluprost $0.0015 \% /$ timolol $0.5 \%$ FC provides clinically and statistically significant IOP reductions in patients with open-angle glaucoma and ocular hypertension. The IOP reductions are superior 
to those achieved after administering the individual components, PF tafluprost $0.0015 \%$ and PF timolol $0.5 \%$. The PF FC tafluprost/ timolol was well tolerated and safe, and associated with a low prevalence of conjunctival hyperemia.

\section{ACKNOWLEDGMENTS}

Sponsorship and article processing charges for this study were provided by Santen Oy, Tampere, Finland. The sponsor participated in the design of the study, conducting of the study, data collection, data management, data analysis, data interpretation, and the preparation, review, and approval of the manuscript. Medical writing and editorial assistance were provided by Friedemann Kimmich, eyecons, Pfinztal, Germany and funded by Santen Oy. All authors had full access to all of the data in this study and take complete responsibility for the integrity of the data and accuracy of the data analysis. All named authors meet the ICMJE criteria for authorship for this manuscript, take responsibility for the integrity of the work as a whole, and have given final approval to the version to be published.

Conflict of interest. Norbert Pfeiffer has received research grants and speaker honorariums from Santen Oy, Tampere, Finland, and has received an unrestricted research fund from the Sir Emeka Offor Foundation (Abuja, Nigeria). Carlo Traverso, Katrin Lorenz, Ville Saarela, Johanna Liinamaa, Hannu Uusitalo, Yury Astakhov and Ernest Boiko have received research grants and speaker honorariums from Santen Oy, Tampere, Finland. Auli Ropo is an employee of Santen Oy, Tampere, Finland.
Compliance with ethics guidelines. All procedures followed were in accordance with the ethical standards of the responsible committee on human experimentation (institutional and national) and with the Helsinki Declaration of 1975 , as revised in 2000 and 2008. Informed consent was obtained from all patients for being included in the study.

Open Access. This article is distributed under the terms of the Creative Commons Attribution Noncommercial License which permits any noncommercial use, distribution, and reproduction in any medium, provided the original author(s) and the source are credited.

\section{APPENDIX}

The following investigators participated in this multicenter clinical trial: The Preservative-free Tafluprost Fixed Combination Study Group:

Hannu Uusitalo (Tampere, Finland), Kai Kaarniranta (Kuopio, Finland), Ville Saarela (Oulu, Finland), Norbert Pfeiffer (Mainz, Germany), Ulrich Bartz-Schmidt (Tuebingen, Germany), Stephan Dunker (Troisdorf, Germany), Thomas Hamacher (Starnberg, Germany), Klaas Heidemann (Leer, Germany), Günter Hofmann (Schweinfurt, Germany), Ines Lanzl (Prien, Germany), Karin Oehmig (Chemnitz, Germany), Gernot Petzold (Kulmbach, Germany), Ulrich Richter (Regensburg, Germany), Ulrich Thelen (Muenster, Germany), Axel Zehe (Dresden, Germany), Marie-Luise Scherzer (Regenstrauf, Germany), Nathalie Collignon (Liège, Belgium), U.F. Tegelberg (Goes, Netherlands), Carlo Enrico Traverso (Genoa, Italy), Mirella Blini (Milan, Italy), Emilio Campos (Bologna, Italy), Marco Centofanti (Rome, Italy), Federico 
Grignolo (Turin, Italy), Gianluca Manni (Rome, Italy), Enrico Martini (Sassuolo, Italy), Nicola Pescosolido (Rome, Italy), Luciano Quaranta (Brescia, Italy), Odilia Vattovani (Trieste, Italy), Giuseppe Ravalico (Trieste, Italy), Luca Rosetti (Milan, Italy), Vincenzo Russo (Foggia, Italy), Adolfo Sebastiani (Ferrara, Italy), Hana Garzozi (Haifa, Israel), Orna Geyer Haifa, Israel), Shimon Kurtz (Tel Aviv, Israel), Moshe Lusky (Petach Tikva, Israel), Ronit Nesher (Kfar-Saba, Israel), Miriam Zalish (Rehovot, Israel), Simon Longstaff (Sheffield, United Kingdom), Rupert Bourne (Huntingdon, United Kingdom), Timothy Manners (York, United Kingdom), Velota Sung (Birmingham, United Kingdom), Jósef Kaluzny (Bydgoszcz, Poland), Danuta Karczewicz (Szczecin, Poland), Marta MisiukHojlo (Wroclaw, Poland), Jerzy Nawrocki (Lodz, Poland), Wanda Romaniuk (Katowice, Poland), Malgorzata Siewierska (Kraków, Poland), Edward Wylegala (Bielsko-Biala, Poland), Tomasz Zarnowski (Lublin, Poland), Kuldar Kaljurand (Tartu, Estonia), Kai Noor (Tallinn, Estonia), Kadri Tammeaid (Tallinn, Estonia), Natalie Feldmann (Kohtla-Jaerve, Estonia), Krista Turman (Tallin, Estonia), Evgeniy Egorov (Moscow, Russia), Valeriy Erichev (Moscow, Russia), Ernest Boiko (St. Petersburg, Russia), Yury Astakhov (St. Petersburg, Russia), Vladimir Alexeev (St. Petersburg, Russia), Alla Ryabteva (Moscow, Russia).

\section{REFERENCES}

1. Kass MA, Heuer DK, Higginbotham EJ, et al. The Ocular Hypertension Treatment Study. A randomized trial determines that topical hypotensive medication delays or prevents the onset of primary open-angle glaucoma. Arch Ophthalmol. 2002;120:701-13.

2. Coleman AL, Miglior S. Risk factors for glaucoma onset and progression. Surv Ophthalmol. 2008;53:S3-10.
3. European Glaucoma Society. Terminology and Guidelines for Glaucoma. 4th ed. Savona: PubliComm; 2014. p. 141.

4. Olthoff CM, Schouten JS, van de Borne BW, Webers CA. Noncompliance with ocular hypotensive treatment in patients with glaucoma or ocular hypertension an evidence-based review. Ophthalmology. 2005;112:953-61.

5. Higginbotham EJ. Considerations in glaucoma therapy: fixed combinations versus their component medications. Clin Ophthalmol. 2010;4:1-9.

6. Baudouin C. Side effects of antiglaucomatous drugs on the ocular surface. Curr Opin Ophthalmol. 1996;7:80-6.

7. Patel SC, Spaeth GL. Compliance in patients prescribed eyedrops for glaucoma. Ophthalmic Surg. 1995;26:233-6.

8. Sleath B, Robin AL, Covert D, Byrd JE, Tudor G, Svarstad B. Patient-reported behavior and problems in using glaucoma medications. Ophthalmology. 2006;113:431-6.

9. Liang H, Baudouin C, Pauly A, Brignole-Baudouin F. Conjunctival and corneal reactions in rabbits following short- and repeated exposure to preservative-free tafluprost, commercially available latanoprost and $0.02 \%$ benzalkonium chloride. $\mathrm{Br} \mathrm{J}$ Ophthalmol. 2008;92:1275-82.

10. Liang H, Baudouin C, Labbe A, Riancho L, BrignoleBaudouin F. Conjunctiva-associated lymphoid tissue (CALT) reactions to antiglaucoma prostaglandins with or without BAK-preservative in rabbit acute toxicity study. PLoS One. 2012;7:e33913.

11. Whitson JT, Petroll WM. Corneal epithelial cell viability following exposure to ophthalmic solutions containing preservatives and/or antihypertensive agents. Adv Ther. 2012;29:874-88.

12. Sarkar J, Chaudhary S, Namavari A, et al. Corneal neurotoxicity due to topical benzalkonium chloride. Invest Ophthalmol Vis Sci. 2012;53:1792-802.

13. Kahook MY, Noecker RJ. Quantitative analysis of conjuctival goblet cells after chronic application of topical drops. Adv Ther. 2008;25:743-51.

14. Leung EW, Medeiros FA, Weinreb RN. Prevalence of ocular surface disease in glaucoma patients. J Glaucoma. 2008;17:350-5.

15. Erb C, Gast U, Schremmer D. German register for glaucoma patients with dry eye. I. Basic outcome 
with respect to dry eye. Graefes Arch Clin Exp Ophthalmol. 2008;246:1593-601.

16. Rossi GC, Pasinetti GM, Scudeller L, Raimondi M, Lanteri S, Bianchi PE. Risk factors to develop ocular surface disease in treated glaucoma or ocular hypertensive patients. Eur J Ophthalmol. 2012;23:296-302.

17. Mathews PM, Ramulu PY, Friedman DS, Utine CA, Akpek EK. Evaluation of ocular surface disease in patients with glaucoma. Ophthalmology. 2013;120:2241-8.

18. Jaenen N, Baudouin C, Pouliquen P, Manni G, Figueiredo A, Zeyen T. Ocular symptoms and signs with preserved and preservative-free glaucoma medications. Eur J Ophthalmol. 2007;17:341-9.

19. Pisella PJ, Pouliquen P, Baudouin C. Prevalence of ocular symptoms and signs with preserved and preservative free glaucoma medication. $\mathrm{Br} \mathrm{J}$ Ophthalmol. 2002;86:418-23.

20. Traverso CE, Ropo A, Papadia M, Uusitalo H. A phase II study on the duration and stability of the intraocular pressure-lowering effect and tolerability of Tafluprost compared with latanoprost. J Ocul Pharmacol Ther. 2010;26:97-104.

21. Uusitalo H. Pillunat LE, Ropo A; Phase III, Study Investigators. Efficacy and safety of tafluprost $0.0015 \%$ versus latanoprost $0.005 \%$ eye drops in open-angle glaucoma and ocular hypertension: 24-month results of a randomized, doublemasked phase III study. Acta Ophthalmol. 2010;88:12-9.

22. Konstas AG, Quaranta L, Katsanos A, et al. Twentyfour hour efficacy with preservative free tafluprost compared with latanoprost in patients with primary open angle glaucoma or ocular hypertension. Br J Ophthalmol. 2013;97:1510-5.

23. Webers CA, Beckers HJ, Zeegers MP, Nuijts RM, Hendrikse F, Schouten JS. The intraocular pressurelowering effect of prostaglandin analogs combined with topical $\beta$-blocker therapy: a systematic review and meta-analysis. Ophthalmology. 2010;117(2067-74):e1-6.

24. Cheng JW, Cheng SW, Gao LD, Lu GC, Wei RL. Intraocular pressure-lowering effects of commonly used fixed-combination drugs with timolol: a systematic review and meta-analysis. PLoS One. 2012;7:e45079.

25. Egorov E, Ropo A. Investigators. Adjunctive use of tafluprost with timolol provides additive effects for reduction of intraocular pressure in patients with glaucoma. Eur J Ophthalmol. 2009;19:214-22.
26. Holló G, Hommer A, Antón López A, Ropo A. Efficacy, safety, and tolerability of preservative-free fixed combination of tafluprost $0.0015 \% /$ timolol $0.5 \%$ versus concomitant use of the ingredients. J Ocul Pharmacol Ther. 2014;30:468-75.

27. Robin AL, Novack GD, Covert DW, Crockett RS, Marcic TS. Adherence in glaucoma: objective measurements of once-daily and adjunctive medication use. Am J Ophthalmol. 2007;144:533-40.

28. Fechtner RD, Godfrey DG, Budenz D, Stewart JA, Stewart WC, Jasek MC. Prevalence of ocular surface complaints in patients with glaucoma using topical intraocular pressure lowering medications. Cornea. 2010;29:618-21.

29. Uusitalo H, Chen E, Pfeiffer N, et al. Switching from a preserved to a preservative-free prostaglandin preparation in topical glaucoma medication. Acta Ophthalmol. 2010;88:329-36.

30. Chabi A, Varma R, Tsai JC, et al. Randomized clinical trial of the efficacy and safety of preservative-free tafluprost and timolol in patients with open-angle glaucoma or ocular hypertension. Am J Ophthalmol. 2012;153:1187-96.

31. Pellinen P, Lokkila J. Corneal penetration into rabbit aqueous humor is comparable between preserved and preservative-free tafluprost. Ophthalmic Res. 2009;41:118-22.

32. de Jong C, Stolwijk T, Kuppens E, de Keizer R, van Best J. Topical timolol with and without benzalkonium chloride: epithelial permeability and autofluorescence of the cornea in glaucoma. Graefes Arch Clin Exp Ophthalmol. 1994;232:221-4.

33. Pfeiffer N, European Latanoprost Fixed Combination Study Group. A comparison of the fixed combination of latanoprost and timolol with its individual components. Graefes Arch Clin Exp Ophthalmol. 2002;240:893-9.

34. Brandt JD, Cantor LB, Katz LJ, Batoosingh AL, Chou C, Bossowska I, Ganfort Investigators Group II. Bimatoprost/timolol fixed combination: a 3-month double-masked, randomized parallel comparison to its individual components in patients with glaucoma or ocular hypertension. J Glaucoma. 2008;17:211-6.

35. Barnebey HS, Orengo-Nania S, Flowers BE, et al. The safety and efficacy of travoprost $0.004 \%$ /timolol $0.5 \%$ fixed combination ophthalmic solution. Am J Ophthalmol. 2005;140:1-7.

36. Stewart WC, Konstas AG, Nelson LA, Kruft B. Metaanalysis of 24-h intraocular pressure studies 
evaluating the efficacy of glaucoma medicines. Ophthalmology. 2008;115(1117-22):e1.

37. Konstas AG, Nakos E, Tersis I, Lallos NA, Leech JN, Stewart WC. A comparison of once-daily morning vs evening dosing of concomitant latanoprost/ timolol. Am J Ophthalmol. 2002;133:753-7.

38. Konstas AG, Tsironi S, Vakalis AN, et al. Intraocular pressure control over $24 \mathrm{~h}$ using travoprost and timolol fixed combination administered in the morning or evening in primary open-angle glaucoma and exfoliative glaucoma. Acta Ophthalmol. 2009;87:71-6.

39. Konstas AG, Holló G, Mikropoulos D, et al. Twentyfour-hour intraocular pressure control with bimatoprost and the bimatoprost/timolol fixed combination administered in the morning, or evening in exfoliative glaucoma. Br J Ophthalmol. 2010;94:209-13. 